\title{
Evaluate the influence of stable and unstable platform on strength and work capacity of abdominal muscles during instability resistance abdominal muscles training.
}

\author{
Balaji palniappan ${ }^{1}$, R. Chidambaram ${ }^{2}$, Deivendran Kalirathinam ${ }^{3}$ \\ ${ }^{1}$ Reader in Physiotherapy, Division of Physical Medicine and Rehabilitation, RMMC\&H, \\ ${ }^{2}$ Annamalai university, Annamalai nagar,Tamil nadu India 21Associate professor, Modern College of \\ Physiotherapy, Shivaji nagar, Pune, Maharastra,India. \\ ${ }^{3}$ Associate Professor, MAEER'SPhysiotherapy College MIMER Medical College \& Hospital, Talegaon \\ Dhabade, Pune, Maharastra, India .
}

\begin{abstract}
Background: Abdominal strength is required for preventing injuries in athletes as well as in normal individual. So to improve abdominal strength we can choose many ways that includes exercise on Flat bench, on Swiss ball etc, will help in improving abdominal strength. Purpose of the study: The purpose of this study was to evaluate the influence of stable and unstable platform on strength and work capacity of abdominal muscles during instability resistance abdominal muscles training. Method: 19-25 years old 30 female subjects with BMI range from 18.5 to 23 from the student community of a physical therapy college were selected through convenient sampling method, subjects were divided into two groups of 15 subjects each. The control got only the conventional method of abdominal and low back muscle strength training by recruit them in flat barbell chest exercise. The experimental group got the barbell chest exercise in swiss ball. The exercise was repeated for 5 times with maximum weight with advent of calculated 1 RM with 2 sessions for 7 days. The variables of interest 1 RM and Abdominal Muscle Strength through Sit-up test as a functional outcome measure of abdominal strength was measured after and before the intervention. Results: Baseline values of demographic and variables of interest were homogenous in both groups with $p>0.05$. There was statistically significant improvement within group for both variables of interest with $p<0.05$ where there was not statistically significant improvement between groups for both variables of interest with $p>0.05$. Conclusion: There is no statistically significant difference in 1 RM and abdominal muscle strength in between the Flat Bench and Swiss Ball Groups while there is significant improvement in both groups individually after the intervention of abdominal muscle strengthening exercises.
\end{abstract}

Keywords: abdominal muscles, instability resistance training, swiss ball, flat bench

Submitted Date 25 June 2013

Accepted Date: 01 July 2013

\section{Back Ground}

Many adults begin an exercise program with the aim of reducing their spare tyre and athletes often feel that a strong mid section is important. These two factors make abdominal strengthening exercise tremendously popular for fitness training and sports ${ }^{1}$.

Stability ball exercises are often central to a program designed to improve core stability. In recent years, health and fitness practitioners have given greater and greater emphasis to core stability training for injury prevention, rehabilitation and performance enhancement.

The concept of developing strong muscles in the trunk is believed to reduce the risk of both acute and chronic injury and weak core muscles have been associated with low back pain ${ }^{2,3}$. Core stability can also improve athletic performance as rapid and controlled limb movement is directly related to the ability of the core muscles to stabilize the spine ${ }^{4,5}$.

Instability training, or training with the use of unstable loads and/or platforms, has only recently begun to emerge and become recognized as an effective strategy, by itself and/or in combination with added resistance (instability resistance training), at increasing core (trunk/torso) stability and potentially improving task performance through facilitated spinal and postural stability ${ }^{5-6}$. This stability is provided by strength, endurance, and neuromuscular coordination of prime movers and stabilizers, in particular the trunk muscles which get activated to a greater extent as movements become moderately unstable ${ }^{7-9}$.

Research from the rehabilitation literature has demonstrated the effectiveness of core stability type exercises for treating or preventing lower back and lower and upper extremity injuries ${ }^{10-14}$. Core stability exercises performed for rehabilitation purposes are often performed on unstable equipment such as a Swiss ball, wobble board, low density mat, or air filled disc ${ }^{15}$. 
The role of core muscle is to stabilize or protect the spine from hazardous forces. The forces may be transfer from extremity to the trunk through core muscles ${ }^{16}$. Core muscles are not only the rectus abdominis but it includes muscles like transvers abdominis, multifidus external oblique,internal oblique etc ${ }^{17}$.

Researchers suggest that strong and endurable core muscles stabilize the spine favorably by providing greater passive support with effective mechanical integrity and enhanced neurological recruitment patterns; including timely activation of these muscles when exposed to forces and loads ${ }^{18-20}$.

It has been suggested that an increase in instability of the surface to human body interface will stress the neuromuscular system to a greater degree than stable resistance training methods performed on solid ground 21 .

One rep max is the amount of weight you can lift for a given exercise one time only ${ }^{22}$. It is a great indicator of strength and, in some cases, fitness level. However performing a one rep max can be dangerous. It is recommended that you use a safer method, such as finding out how much weight you can lift for, say, 10 repetitions. This equation will convert that weight into your one rep max. Abdominal Strength Test which is 1 Minute sit up test is an easy to perform test of abdominal strength. Purpose of this 1 Minute sit up test measures abdominal strength, which is important in back support and core stability ${ }^{23-26}$.

The main aim is to prevent the unfortunate ill effects of sedentary life style in normal adults and to improve the functional ability of modern adults in the form of physical fitness through various measures like barbell chest press on movable and stable surface.

The purpose of this study was to evaluate the influence of stable and unstable platform on strength and work capacity of abdominal muscles during instability resistance abdominal muscles training.

\section{Methodology}

69 female volunteers from a physiotherapy college in the age of 19-25 years with BMI of 18.5-24.9 were randomly allotted by closed envelope method into two groups having 34 in control group (flat bench) and 35 in experimental group (swiss ball). Subject's Demographic variables like Age, Sex and their BMI were recorded. The control group received only the conventional method of abdominal and low back muscle strength training by recruit them in flat barbell chest exercise. The experimental group received the barbell chest exercise in swiss ball. The exercises were repeated for 5 times with maximum weight with advent of calculated 1 RM with 2 sessions for 7 days. After 7 days of intervention post interventional scores of variables of interest 1 RM and Abdominal Muscle Strength was measured again and documented for data analysis.

$1 \mathrm{RM}$ was measured by using the following formula, $1 \mathrm{RM}=$ WEIGHT used $/(1.0278-(0.0278 \mathrm{x}$ Number of Reps). Abdominal muscle strength was measured by 1 MINUTE SIT UP TEST as follows, the subjects were advised to lie on a carpeted or cushioned floor with knees bent at approximately right angles, with feet flat on the ground. Their hands should be resting on thighs then the subject asked to squeeze stomach, push back flat and raise high enough for their hands to slide along the thighs to touch the tops of their knees. During this subjects were instructed not to pull with their neck or head and keep their lower back on the floor. Then the subjects were asked to return to the starting position. Repetitions in one minute were counted and documented. Data were analyzed by using student $t$ test with spss 16.0 version for windows. $\mathrm{P} \leq 0.05 \mathrm{kept}$ as significant for all analysis.

\section{Data Analysis And Results}

Table 1: Analysis of Demographic Variables - Age and BMI in Swiss Ball Group and Flat Bench Group

\begin{tabular}{|l|l|l|l|l|}
\hline Variable & $\begin{array}{l}\text { Mean } \pm \text { SD } \\
\text { (Flat Bench) }\end{array}$ & $\begin{array}{l}\text { Mean } \pm \text { SD } \\
\text { (Swiss ball) }\end{array}$ & 't' value & P value \\
\hline Age & $23.00 \pm 1.57$ & $22.89 \pm 1.37$ & -0.359 & 0.729 \\
\hline BMI & $22.33 \pm 1.45$ & $20.96 \pm 1.68$ & -1.944 & 0.088 \\
\hline
\end{tabular}

Table 1 shows the pre test values of Demographic Variables of Age, BMI in Flat bench and Swiss ball group. Baseline democratic variables were analyzed by independent $t$ test showing $p>0.05$ ascertains the homogeneity of groups.

Table 2: Within groups comparison of 1 RM and Abdominal Strength in Swiss Ball Group and Flat Bench Group

\begin{tabular}{|l|l|l|l|l|l|}
\hline Group & Variable & $\begin{array}{l}\text { Pre } \\
\text { Mean } \pm \text { SD }\end{array}$ & $\begin{array}{l}\text { Post } \\
\text { Mean } \pm \text { SD }\end{array}$ & 't'value & P value \\
\hline Flat Bench & $1 \mathrm{RM}$ & $13.83 \pm 2.01$ & $16.77 \pm 1.73$ & -4.992 & 0.001 \\
\hline Swiss Ball & $1 \mathrm{RM}$ & $15.19 \pm 1.05$ & $21.01 \pm 1.78$ & -8.764 & 0.000 \\
\hline Flat Bench & $\begin{array}{l}\text { Abdominal } \\
\text { Strength }\end{array}$ & $30.11 \pm 1.67$ & $37.78 \pm 1.97$ & -9.021 & 0.000 \\
\hline Swiss Ball & $\begin{array}{l}\text { Abdominal } \\
\text { Strength }\end{array}$ & $33.18 \pm 1.86$ & $40.64 \pm 2.23$ & -5.518 & 0.000 \\
\hline
\end{tabular}


Table 2 shows pre and post intervention values of 1 RM and Abdominal Muscle Strength in Flat bench and Swiss ball Group with $\mathrm{p}<0.05$ for respective groups suggests that there was improvement in 1RM and abdominal muscle strength after the intervention in both the groups.

Table 3: Between groups comparison of 1 RM and Abdominal Strength in Swiss Ball Group and Flat Bench Group

\begin{tabular}{|l|l|l|l|l|l|}
\hline Variable & Flat Bench & Swiss Ball & 't' value & P value \\
\hline Pre & $1 \mathrm{RM}$ & $13.83 \pm 2.01$ & $15.19 \pm 1.05$ & .912 & .367 \\
\cline { 2 - 6 } Mean \pm SD & $\begin{array}{l}\text { Abdominal } \\
\text { Strength }\end{array}$ & $30.11 \pm 1.67$ & $33.18 \pm 1.86$ & 1.067 & .300 \\
\hline $\begin{array}{l}\text { Post } \\
\text { Mean } \pm \text { SD }\end{array}$ & $1 \mathrm{RM}$ & $16.77 \pm 1.73$ & $21.01 \pm 1.78$ & .751 & .462 \\
\cline { 2 - 6 } & $\begin{array}{l}\text { Abdominal } \\
\text { Strength }\end{array}$ & $37.78 \pm 1.97$ & $40.64 \pm 2.23$ & .521 & .609 \\
\hline
\end{tabular}

Table 3 shows post intervention values of 1 RM and Abdominal Muscle Strength between Flat bench and Swiss ball group with $\mathrm{p}>0.05$ between groups suggests that there was no statistically significant improvement in 1RM and abdominal muscle strength after the intervention between the groups while pre values with $p>0.05$ ascertain that there was homogeneity in baseline values of variables of interest.

\section{Discussion}

The purpose of study was to determine the effectiveness of barbell chest press exercise on abdominal muscles strength on different surfaces as unstable surface (Swiss Ball) and stable surface (Flat Bench) in young healthy women.

The results supported us to make points clear that there is improvement in abdominal muscles strength after barbell chest press training on stable and unstable surfaces (see table 2). Thus our study strengthen the literature of Cowley PM, Swensen T, Sforzo GA (2007), who stated "Barbell chest-press training performed on either the stability ball or flat bench increased strength and work capacity, and these changes were transferable across platforms. Thus, the stability ball is an effective platform for barbell chest-press training in untrained women over a short duration." 27

But in between the groups the results showed that there was no statistically significant difference in the abdominal core muscle strength (see table 3). This might be due to less duration of exercise performance and both groups were assigned with normal young healthy adults.

And the result endorses the literature of Goodman CA, Pearce AJ, Nicholes CJ, Gatt BM, Fairweather IH. No difference in 1RM strength and muscle activation during the barbell chest press on a stable and unstable surface. "Selected trunk muscle activity during certain upper limb strength training exercises is not consistently influenced by the replacement of an exercise bench with a swiss ball". ${ }^{28}$

From these results we find that this study was performed for 2 sessions of 10 repetitions for 1 week period. This may be a very limited time and abdominal strengthening exercises were given in stable (Flat Bench) as well as unstable (Swiss Ball) was not showing significant difference in the results because of these exercises may not be performed perfectly. These things we should take a note of it and in upcoming researches these things should be taken into note.

\section{Conclusion}

There is no statistically significant difference in $1 \mathrm{RM}$ and abdominal muscle strength in between the Flat Bench and Swiss Ball Groups while there is significant improvement in both groups individually after the intervention of abdominal muscle strengthening exercises.

\section{References}

[1]. C.M .Norris MSc MCSP, Abdominal muscle training in sports, Br j Sp Med. 1993: 27(1).

[2]. Hodges PW, Richardson CA. Altered trunk muscle recruitment in people with low back pain with upper limb movement at different speeds. Arch Phys Med Rehabil. 1999 Sep; 80(9):1005-12.

[3]. Hodges PW, Richardson CA. Contraction of the abdominal muscles associated with movement of the lower limb. Phys Ther. 1997 Feb: 77(2):132-42.

[4]. Hodges PW, Richardson CA, Relationship between limb movement speed and associated contraction of the trunk muscles. Ergonomics. 1997 Nov: 40(11):1220-30.

[5]. Vera-Garcia FJ, Grenier SG, McGill SM. Abdominal muscle response during curl-ups on both stable and labile surfaces. Physical Therapy. 2000: 80: 564-66.

[6]. Mori. A, Electromyographic activity of selected trunk muscles during stabilization exercises using a gym ball. Electromyogr. Clin. Neurophysiol. 2004: 44: 57-64.

[7]. Behm, D.G., Power, K.E., and Drinkwater, E.J, Muscle activation is enhanced with multi- and uni-articular bilateral versus unilateral contractions. Canadian Journal of Applied Physiology, 2003: 28: 38-52. 
[8]. Anderson, K. and Behm, D.G, Trunk Muscle Activity Increases with Unstable Squat Movements. Canadian Journal of Applied Physiology, 2005: 30(1): 33-45.

[9]. Arokoski, J.P., T. Valta, O. Airaksinen, M. Kankaanpaa, Back and abdominal muscle function during stabilization exercises. Arch Phys Med Rehabil., 2001: 82: 1089-98.

[10]. Caraffa, A., G. Cerulli, M. Projetti, G. Aisa, And A. Rizzu, Prevention of anterior cruciate ligament injuries in soccer: A prospective controlled study of proprioceptive training. Knee Surg Sports Traumatol Arthrosc. 1994: 4: 19-21.

[11]. Carter, J.M., W.C. Beam, S.G. Mcmahan, M.L. Barr, And L. Brown, The effects of stability ball training on spinal stability in sedentary individuals. J Strength Cond Res. 2006: 20(2): 429 - 435.

[12]. Mcgill, S.M, Low back stability: From formal description to issues for performance and rehabilitation. Exerc Sport Sci Rev. 2001: 29(1): $26-31$.

[13]. Verhagen, E., A. Van Der Beek, J. Twisk, L. Bouter, R. Bahr, And W.V. Mechelen, The effect of a proprioceptive balance board training program for the prevention of ankle sprains. Amer J Sports Med. 2004: 32(6): 1385-93.

[14]. Willardson, J.M, The effectiveness of resistance exercises performed on unstable equipment. Strength Cond J. $2004: 26(3): 70-74$.

[15]. Brumin J, The missing component of core training. Endurance NSCA performance training journal 2004: 3 (6): 16-18.

[16]. Cynthia ST, Arnaud Liggett MPA, Comparison of Abdominal Muscle Strength Following Ball and Mat Exercise Regimens: A Pilot Study The Journal of Manual \& Manipulative Therapy 1999: 7(4): 197 -202.

[17]. Baltimore, Md, "Low back exercise: prescription for the healthy back and when recovering from injury", In American College of Sports Medicine Resource Manual for Guidelines for Exercise Testing and Prescription. $3^{\text {rd }}$ ed. 1998: 116-128.

[18]. Fredericson, M., \& Moore, T, Core stabilization training for middle and long distance runners. New Studies in Athletics, 2005: 20: 25-37.

[19]. Cholewicki, J., Simons, P. A., \& Radebold, A, Effects of external trunk loads on lumbar spine stability. Journal of Biomechanics, 2000: 33: 1377-85

[20]. Hodges, P. W, \& Richardson, C. A, Inefficient muscular stabilization of the lumbar spine associated with low back pain: A motor control evaluation of the transversus abdominis. Spine, 1996: 21: 2640-50.

[21]. McGill, M. S., Grenier, S., Kavcic, N., \& Cholewicki, J, Coordination patterns of muscle activity to assure stability of the lumbar spine. Journal of Electromyography and Kinesiology, 2003: 13: 353-59.

[22]. Behm, G. D., Anderson, K., Curnew, S. R, Muscle force and activation under stable and unstable conditions. Journal of Strength and Conditioning Research, 2002: 16: 416-22.

[23]. Brzycki. M, Strength testing: Predicting a one-rep max from a reps-to-fatigue Journal of Physical Education, Recreation and Dance, 1993: 64 (1): 88-90.

[24]. ACSM, Guidelines for Exercise Testing and Prescription, $4^{\text {th }}$ Edition, Lea and Febiger, 1991.

[25]. ACSM, Resource Manual for Guidelines for Exercise Testing and Prescription, Lea and Febiger, 1988.

[26]. Government of Canada, Fitness and Amateur Sport, Canadian Standardized Test of Fitness, 1986 Operation Manual.

[27]. Cowley PM, Swensen T, Sforzo GA: Efficacy of instability resistance training. Int J Sports Med. 2007 Oct: 28(10):829-35.

[28]. Goodman CA, Pearce AJ, Nicholes CJ, Gatt BM, Fairweather IH, No difference in 1RM strength and muscle activation during the barbell chest press on a stable and unstable surface. J Strength Cond Res. 2008 Jan: 22(1): 88-94. 